\title{
A tribute to Ketty Schwartz
}

ur colleague and friend Ketty Schwartz died on December 25, 2007. A petite woman with a commanding presence, Ketty devoted her distinguished scientific career to the study of heart and skeletal muscle biology and pathology. Ketty received her doctorate from the University of Paris, where her thesis focused on the preservation of heart and liver organs. She also received a certificate in general immunology from the Pasteur Institute. Initially she was codirector of the Laboratory of Biochemistry in the Center for Surgical Techniques at the Broussais Hospital in Paris, and then she became director of two INSERM units in Paris. Ultimately, she became Director General of French Research at the Ministry of Research in Paris, the top research policy position in France. In this position she exercised great influence in forming French research policy and was recognized as one of the highest ranking women in science in the world.

Her early contributions delved deeply into the differences between sarcomere proteins from skeletal and cardiac muscle. Using creative biochemical and molecular biologic approaches, she provided fundamental knowledge about changes in isoform expression that accompanied muscle development, physiologic growth, and pathologic hypertrophy. Despite amassing a formidable repertoire of scientific techniques, in the early 1990s Ketty elected to expand her investigative armamentarium to include human genetics, and again her success was considerable, with the discovery of many myopathic disease loci, genes, and mutations. Armed with both profound understanding of muscle biology and precise knowledge of DNA defects, Ketty refocused her scientific toolbox again, harnessing gene- and cellbased strategies to devise novel treatments for muscular dystrophy and heart failure.

Biochemistry, molecular biology, human genetics, gene therapy, and myoblast transplantation - employing so vast an array of technically demanding scientific approaches should be nearly impossible for one researcher, even one as talented as Ketty Schwartz. So how did she do it? By team science; Ketty was deeply committed to collaboration and cooperation beyond her institutional academic unit and forged worldwide alliances so as to tackle any problem. Even in casual conversation, Ketty's belief in the power of a team approach was evident. When discuss- ing a new finding or idea she began with a quintessential prologue - "the XX team has discovered or suggested that ...." Or when introducing her question after a presentation she began with "congratulations to your team ... now let me ask you ...."

Though we doubt that she was ever a committed fan of sports, Ketty's ability to coach a team was second to none. We learned this first-hand in 1992 during the early days of mapping hypertrophic cardiomyopathy disease genes. She assembled an international group of basic researchers and clinicians - specialists in cardiac imaging, electrophysiology, and human molecular genetics - to define strategies to enable productive genome-wide linkage studies. Competitive groups from major centers in the US, UK, France, Italy, and Germany came and over several days debated and argued and agreed to disagree, but remarkably, not one participant left early - perhaps worried

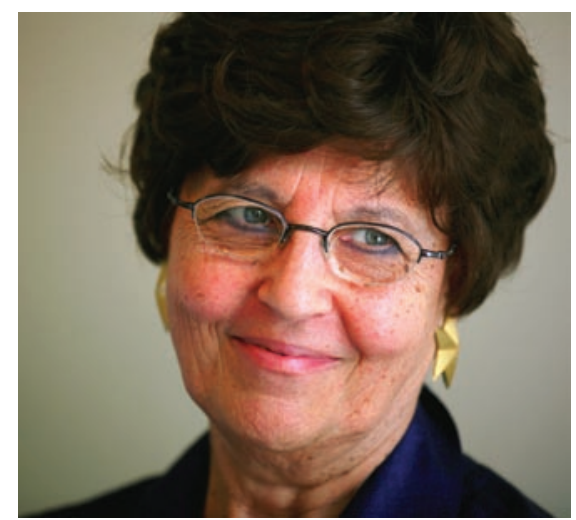

about missing some insight into a competitor's approach or data, or perhaps because by sharing, everyone's science got better. That meeting predestined the development of more formal approaches for team science, including working groups and networks that are so popular today.

Ketty's construction of teams went well beyond the inclusion of researchers from scientifically diverse disciplines. She engaged patients, families, advocacy groups, ethicists, and funding agencies in her teams, a strategy that motivated young and seasoned investigators to work together. As the founding member of the Scientific Council of the Association Française contre les Myopathies, and then as its president (since 1998), she developed interdisciplinary research teams devoted to understanding cardiac and skeletal muscle diseases. Her work led to the establishment of DNA banks with linked patient registries that have helped propel discovery of genetic causes and continue to promote collaborative clinical trials. She served on France's National Advisory Committee on Ethics for the Life Sciences and Health and was president of the INSERM reflection group with patients' associations (GRAM), which endorses policies that promote partnership and dialogue between researchers and patient associations. More broadly, her efforts in multidisciplinary team building helped to fuel the creation of clinical and research networks within Europe and with the US.

Later in her career, Ketty became very actively involved in efforts to counteract attempts to boycott Israeli academics. She made numerous trips to Israel, where she organized international scientific conferences, commenting, "I never realized how important my Jewish heritage was to me until I made these trips to Israel.”

Ketty was a pioneer in many ways, and a role model to many of us. Her sensitivity, kindness, and firm but balanced approach to science provide an impressive standard for our community to emulate. And as Ketty's seminal contributions to science are remembered, we should also take inspiration from her strategic and egalitarian approach to team building. Never allowing herself to be distracted by the complexity of a problem, she motivated researchers, patients, donors, and administrators to work together, to accomplish much, and to equally share the fruits of success. While Ketty's vision for collaborative science will live on in the teams of colleagues and collaborators fortunate to have been touched by her, we will sorely miss her leadership, her wisdom, and her zeal.

\section{Christine E. Seidman and Andrew R. Marks}

Department of Genetics, Harvard Medical School, and Howard Hughes Medical Institute, Boston, Massachusetts, USA. E-mail: cseidman@genetics.med.harvard.edu (C. Seidman). Clyde and Helen Wu Center for Molecular Cardiology and Department of Physiology and Cellular Biophysics, Columbia University, New York, New York, USA. E-mail: arm42@columbia.edu (A.R. Marks). 